Jurnal Sistim Informasi dan Teknologi
https://jsisfotek.org/index .php

\title{
Evaluasi Kualitas Jaringan Internet Pemerintah Daerah Kota Padang Panjang Menggunakan Metode Quality of Service
}

\author{
Indah Permata Sari ${ }^{1 凶}$ \\ ${ }^{1}$ Independent Researcher \\ indahpermatasari1598@out1ook.com
}

\begin{abstract}
The Internet network during a pandemic as it is today is the main actor in all aspects. For example, obtaining information, economics, offices, education, and many more. On September 20, 2021, the City of Padang Panjang is included in the Level 3 area, sourced from the circular letter of the Minister of Home Affairs number 44 of 2021 concerning the implementation of restrictions on community activities at level 4 , level 3, level 2, and level 1 . level 3. 50\% of the total number of employees in an office must be WFH (Work From Home) where employees continue to work as usual but stay at home. Then in the field of education $50 \%$ of students and teachers carry out online learning or lectures. From the explanation above, it has been illustrated how important a network is today. Employees can continue to work only from home by relying on the Internet Network. Students and students can still get an education even if they don't go to school and campus. And the Internet network plays a big role in that. Padang Panjang City currently has a Smart City program.
\end{abstract}

Keywords: Mosque, Smart City, Networking, Internet, Quality of Service.

\begin{abstract}
Abstrak
Jaringan Internet saat pandemi seperti saat ini merupakan aktor utama dalam segala aspek. Contohnya memperoleh informasi, ekonomi, perkantoran, pendidikan, dan banyak lagi. Pada tanggal 20 September 2021, Kota Padang Panjang termasuk kawasan Level 3, bersumber dari surat edaran Menteri dalam negeri nomor 44 tahun 2021 tentang pemberlakuan pembatasan kegiatan masyarakat level 4, level 3, level, 2, dan level 1. Maka pada wilayah yang ditetapkan pada level 3. 50\% dari jumlah pegawai yang ada di sebuah kantor harus WFH (Work From Home) yang di mana para pegawai tetap bekerja seperti biasa namun tetap tinggal dirumah. Lalu di bidang pendidikan 50\% siswa dan guru melaksanakan belajar atau kuliah daring. Dari penjelasan di atas sudah tergambar bagaimana pentingnya sebuah jaringan saat ini. Pegawai bisa terus bekerja hanya dari rumah dengan mengandalkan Jaringan Internet. Para siswa dan mahasiswa tetap bisa memperoleh pendidikan meskipun tidak pergi ke sekolah dan ke kampus. Dan Jaringan Internet berperan besar dalam hal itu. Kota Padang Panjang saat ini memiliki program Smart City.
\end{abstract}

Kata kunci: Masjid, Smart City, Jaringan, Internet, Quality of Service.

(c) 2022 JSisfotek

\section{Pendahuluan}

Perkembangan dunia telekomunikasi saat ini berkembang dengan pesat. Teknologi menyebabkan kebutuhan jaringan komunikasi terus menjadi bertambah. Buat melaksanakan transfer infromasi ataupun pertukaran informasi awal mulanya hanya lewat hard copy berbentuk tulisan tangan, dokumen, laporan bulanan hanya memakai link informasi, ikatan antara node-node diresmikan memakai kabel maupun mengunakan media nirkabel.

Jaringan komputer merupakan suatu jaringan telekomunikasi yang membolehkan node-node buat silih berbagi sumber daya (resources). Pada jaringan komputer yang tersambung pada jaringan yang melaksanakan pertukaran informasi dengan komputer lainnya dikala ini sudah tumbuh dalamjaringan internet yang lebih efisien serta efektif [1].

Jaringan tradisional telah dirancang untuk menyediakan data dibagi antara dua atau lebih pengguna. Namun, pemahaman data digantikan oleh layanan seperti push and talk, Voice over IP (VoIP), telepresence, game online, e-learning,

telemedis. Layanan ini telah menjadi kebutuhan vital bagi Internet pengguna apakah mereka individu atau perusahaan, yang berarti bahwa kebutuhan untuk akses segera dan terus menerus dan dengan Kualitas Layanan (QoS) tertinggi tidak dapat disangkal dan yang paling penting [2].

Quality of Service merupakan metode pengukuran tentang seberapa baik jaringan dan merupakan suatu usaha untuk mendefenisikan karakteristik dan sifat dari suatu servis. Qos digunakan untuk mengukur sekumpulan atribut kinerja yang telah dispesifikasikan dan diasosiasikan dengan suatu servis [3].

Kualitas layanan (QoS) ialah sekumpulan teknologi yang bekerja pada jaringan untuk menjamin kemampuannya dalam melaksanakan aplikasi serta lalu lintas prioritas besar secara andal dalam kapasitas jaringan yang terbatas. Teknologi QoS mencapai hal ini dengan menyediakan penindakan yang berbeda

Diterima: 22-02-2022 | Revisi: 01-03-2022 | Diterbitkan: 31-03-2022 | doi: 10.37034/jsisfotek.v4i1.116 
dengan serta alokasi kapasitas buat aliran tertentu dalam lalu lintas jaringan, dalam menajemen jaringan terdapat sebagian parameter kuantitatif khususnya, delay, packet loss, troughpu, jitter serta Bandwitch yang mempunyai ikatan erat dengan kinerja jaringan QoS [4].

Quality of Service (QoS) merupakan teknik yang digunakan untuk mengelola throughput, delay, jitter dan packet loss untuk aliran paket data dalam jaringan internet. Tujuan dari metode Quality of Service (QoS) adalah mempengaruhi salah satu dari beberapa parameter dasar Quality of Service (QoS) yang telah ditentukan [5].

Meskipun kualitas layanan (QoS) telah diselidiki dan diimplementasikan pada jaringan TCP/IP dan pusat data [3], mekanismenya sebagian besar masih belum dijelajahi dalam konteks jaringan HPC. Pekerjaan kami adalah salah satu studi awal untuk menyelidiki peran kelas lalu lintas QoS dalam mengurangi variabilitas kinerja disebabkan oleh terputusnya komunikasi dalam jaringan hierarkis yang sekarang popular [4].

Studi tentang faktor-faktor yang mempengaruhi QoS computer jaringan telah menerima banyak perhatian. Studi tentang pengaruh bandwidth transmisi data saluran dilakukan di. Analisis dari

pengaruh arsitektur sistem komputer dan jaringan komputer. Itu makalah dikhususkan untuk analisis antrian paket dan pengembangan pendekatan terpadu untuk mendiagnosa QoS sistem komputer dan jaringan. Di dalam Selain itu, ada pertanyaan terpisah tentang hubungan indikator QoS dan pemenuhan persyaratan untuk transaksi sistem komputer. Dalam parameter dasar telekomunikasi dasar jaringan yang mempengaruhi kualitas pelaksanaan transaksi sistem komputer diidentifikasi. Secara khusus, itu adalah menunjukkan bahwa ketika memilih platform khusus dengan kontrol terpusat (konvergen dan hiperkonvergen), sinkronisasi sistem komputer memainkan peran penting [6].

Penelitian di bidang telekomunikasi sering mengacu pada untuk topik penelitian ini. Pada akhir abad ke-20, sejumlah besar studi model dilakukan untuk mengevaluasi jitter, delay dan parameter kualitas layanan lainnya [7].

Wifi merupakan salah satu teknologi yang banyak digunakan pada saat ini yakni suatu area dimana suatu koneksi internet dapat berlangsung tanpa kabel. Wifi menjadi teknologi alternatif dan relatif lebih mudah untuk digunakan dilingkungan tempat tinggal, kampus, lingkungan kerja, dan ditempat umum. Dengan teknologi ini individu dapat mengakses jaringan internet melalui perangkat notebook/laptop/handphone di berbagai lokasi dimana hotspot disediakan dengan adanya layanan hotspot diharapkan akan mempercepat akses informasi [8].
Topologi menggambarkan struktur dari suatu jarin gan atau bagaimana sebuah jaringan didesain. Dalam definisi topologi terbagi menjadi dua, y aitu topologi fisik (physical topology) yang $\mathrm{m}$ enunjukan posisi pemasangan kabel secara fisik dan topologi logik (logical topology) yang menunjukan bagaimana

suatu media diakses oleh host. Pada sistem Lan terda pat tiga topologi utama yang paling sering diguna kan: bus, star, dan ring. Topologi jaringan ini ke mudian berkembang menjadi topologi tree dan mes $\mathrm{h}$ yang merupakan kombinasi dari star, mesh, dan bus . Dengan populernya teknologi nirkabel dewasa ini maka lahir pula satu topologi baru yaitu topologi wireless [13].

\section{Metodologi Penelitian}

Pada penelitian ini kegiatan yang dilakukan merupakan bagian dari metode $Q o S$, dan penelitian ini berfokus pada tahap Analisa dan observasi, pengumpulan data, analisa, perancangan, pengujian dan impementasi yang disajikan pada Gamabr 1.

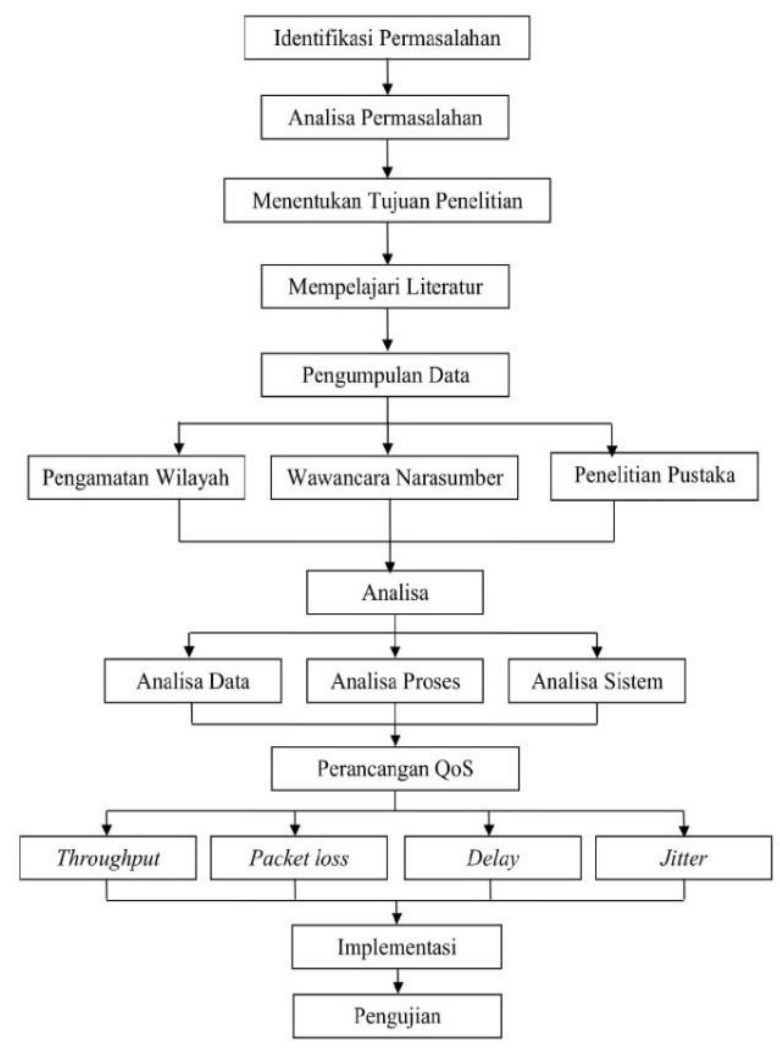

Gambar 1. Kerangka Penelitian

\subsection{Identifikasi Permasalahan}

Proses pengidentifikasian bertujuan sebagai peninjauan objek yang akan diteliti berguna untuk pengamatan serta pencarian permasalahan yang ada. Tahap mengidentifikasi permasalahan merupakan tahap awal dalam melakukan penelitian. 


\subsection{Analisa Permasalahan}

Memahami permasalahan dengan ruang lingkup dan batasan yang sudah ditentukan. Dengan menganalisa permasalahan yang telah ditentukan tersebut.

\subsection{Menentukan Tujuan Permasalahan}

Setelah rumusan permasalahan didapat, selanjutnya menetapkan tujuan. Berguna dalam memperjelas kerangka kerja, ruang lingkup dan batasan permasalahan, serta kegiatan penelitian yang akan dilakukan yang menjadi sasaran utama.

\subsection{Mempelajari Literatur}

Mempelajari literatur berguna dalam memahami metode dan referensi pendukung dalam proses penelitian ataupun dasar-dasar ilmu pengetahuan. Sumber literatur di dapatkan dari dari artikel-artikel serta jurnal penelitian terdahulu yang membahas mengenai metode Quality of Service.

\subsection{Pengumpulan data}

Merupakan tahap pengumpulan informasi-informasi yang diperlukan pada penelitian ini. Beberapa cara pengumpulan data yang digunakan dalam penelitian ini adalah:

a. Pengamatan Wilayah langsung ke lokasi untuk melihat lokasi access point jaringan internet yang terpasang serta data-data yang terkait dengan materi yang dibutuhkan dalam penelitian yang dilakukan.

b. Wawancara Narasumber atau tanya jawab dengan pihak-pihak terkait dengan penelitian sebagai salah satu saranayang dilakukan dalam bertukar informasi serta ide-ide.

c. Penelitian pustaka yaitu mengumpulan data dan informasi dengan cara membaca dan mempelajari buku-buku serta jurnal-jurnal penelitian yang berkaitan dengan penelitian, baik dalam proses penganalisaan data dan informasi, maupun pemecahan masalah secara keseluruhan.

\subsection{Analisa}

Analisa menggunakan Metode Quality of Service Setelah pengumpulan data selesai maka tahapan selanjutnya yaitu melakukan analisis data dengan menerapkan metode Quality Of Service. Adapun tahapan yang dilakukan dalam langkah-langkah pengujian tersebut yaitut:

a. Analisa Data, data-data yang diperoleh adalah jumlah masjid dan OPD yang terpasangi internet dari pemda kota dan jumlah bandwidthnya.

b. Analisa Proses adalah melihat berapa kecepatan internet di masjid dan kantor OPD dengan penerapan bandwithnya, menghitung throughput, packet loss, delay dan jitternya . c. Analisa Sistem adalah menentukan kecepatan internet sesuai dengan index kriteria Nilai QoS seperti pada Tabel 1.

Tabel 1. Index Kriteria Nilai QoS

\begin{tabular}{ccl}
\hline Nilai & Presentasi $(\%)$ & Indeks \\
\hline $3,8-4,00$ & $95,00-100,00$ & Sangat Memuaskan \\
$3,00-3,79$ & $75,00-94,75$ & Memuaskan \\
$2.00-2,99$ & $50,00-74,75$ & Kurang Memuaskan \\
$1,00-1,99$ & $25,00-49,75$ & Tidak Memuaskan \\
\hline
\end{tabular}

\subsection{Perancangan}

Perancangan QoS Menggunakan Metode Quality Of Service Setelah analisa selesai maka tahapan selanjutnya yaitu melakukan perancangan QoS dengan menerapkan metode Quality Of Service. Adapun tahapan yang dilakukan dalam langkah-langkah perancangan tersebut adalah sebagai berikut:

a. Throughput, data-data yang diperoleh adalah jumlah masjid dan OPD yang terpasangi internet dari pemda kota dan jumlah bandwidthnya.

b. Packet loss adalah melihat berapa kecepatan internet di masjid dan kantor OPD dengan penerapan bandwithnya, menghitung throughput, packet loss, delay dan jitternya

c. Delay adalah waktu yang dibutuhkan data untuk menempuh jarak dari asal ke tujuan.

d. Jitter adalah main poin dalam menentukan QoS, dimana jitter mengukur berapa besar ping yang terjadi pada jaringan. Jitter yang tinggi bisa diduga menghasilkan buffering dan error lainnya.

\subsection{Implementasi}

Tahapan selanjutnya yaitu melakukan implementasi. Pada tahap implementasi ini penulis akan melakukan penghitungan untuk mengevaluasi kualitas jaringan di masa sekarang yang bertujuan agar ada perbaikan untuk dimasa mendatang menggunakan rumus QoS dengan standar TIPHON metode Quality of Service.

\subsection{Pengujian}

Tahapan ini dilakukan setelah melakukan perhitungan manual metode Quality of Service dengan hasil dari perhitungan metode Quality of Service menggunakan rumus QoS. Setelah didapat hasilnya maka bisa ditentukan wilayah mana saja yang mengalami masalah jaringan. Setelah itu dilakukan simulasi perbaikan manajemen bandwidth menggunakan perangkat router dan aplikasi mikrotik.

\section{Hasil dan Pembahasan}

Rangkaian hasil penelitian berdasarkan urutan/susunan logis untuk membentuk sebuah cerita. Isinya menunjukan fakta/data dan jangan diskusikan hasilnya. Dapat menggunakan Tabel dan Angka tetapi tidak menguraikan secara berulang terhadap data yang sama dalam gambar, tabel dan teks. Untuk lebih memperjelas uraian, dapat mengunakan sub judul. 
Pembahasan adalah penjelasan dasar, hubungan dan generalisasi yang ditunjukkan oleh hasil. Uraiannya menjawab pertanyaan penelitian. Jika ada hasil yang meragukan maka tampilkan secara objektif.

3.1. Menghitung Throughput, Delay, Packet Loss, Jitter
Untuk menghitung jumlah Troughput, Delay, Packet Loss dan Jitter. Peneliti memakai aplikasi wireshark dan didapati hasil seperti Tabel 1 dan Tabel 2. Setelah itu hasil dari pengukuran dengan Wireshark dimasukkan pada rumus QoS. Perhitungan berikut, yaitu Masjid Jami, Nurul Huda Silaiang Bawah, dan Padang Panjang Barat.

Tabel 2. Pengukuran dengan Wireshark

\begin{tabular}{|c|c|c|c|c|}
\hline Masjid & Trouhgput & Delay & Packet Loss & Jitter \\
\hline Masjid Jami’ Nurul Huda & 21.016 & 1.034 .068 & 48 & 277 \\
\hline Masjid Nurul Iman & & & & 143 \\
\hline Masjid Zu’ama' & & $\mathrm{O}$ & $\mathrm{F}$ & $\mathrm{F}$ \\
\hline Masjid Ashliyah & & $\mathrm{O}$ & $\mathrm{F}$ & $\mathrm{F}$ \\
\hline Masjid Ushuluddin & & $\mathrm{O}$ & $\mathrm{F}$ & $\mathrm{F}$ \\
\hline Masjid Maimunah Ali & 14.996 & 3.570 & 6 & 33 \\
\hline Masjid Nurul Ihsan & 7.067 & 233.959 & 399 & 592 \\
\hline Masjid Nurul Yaqin & & $\mathrm{O}$ & $\mathrm{F}$ & $\mathrm{F}$ \\
\hline Masjid Nurul Khairat & & $\mathrm{O}$ & $\mathrm{F}$ & $\mathrm{F}$ \\
\hline Masjid Al Muttaqin Muhammadiyah & 8.281 & 377.226 & 193 & 698 \\
\hline Masjid Baitul Hikmah & 4.045 & 13.033 & 798 & 17 \\
\hline Masjid Nur Taqwa & 9.067 & 18.045 & 13 & 74 \\
\hline Masjid Tauhid & & $\mathrm{O}$ & $\mathrm{F}$ & $\mathrm{F}$ \\
\hline Masjid Al-Ikhlas & 8.710 & 324.802 & 2 & 500 \\
\hline \multicolumn{5}{|l|}{ Masjid Uswatun Hasanah } \\
\hline Masjid Raya Jihad & & $\mathrm{O}$ & $\mathrm{F}$ & $\mathrm{F}$ \\
\hline \multicolumn{5}{|l|}{ Masjid Syathariyah } \\
\hline Masjid Baiturrahman & 14.429 & 245.417 & 145 & 403 \\
\hline \multicolumn{5}{|l|}{ Masjid Babussalam } \\
\hline \multicolumn{5}{|l|}{ Masjid Hidayah } \\
\hline \multicolumn{5}{|l|}{ Masjid Mujahiddin } \\
\hline \multicolumn{5}{|l|}{ Masjid Barid Al-Munawarah } \\
\hline Masjid Nurul Amri & 8.459 & 631.650 & 27 & 1.110 \\
\hline Masjid Nurul Furqan & 7.560 & 41.367 & 878 & 257 \\
\hline Masjid Taqwa Muhammadiyah & 6.811 & 213.542 & 154 & 411 \\
\hline Masjid Hidayahtussalam & & $\mathrm{O}$ & $\mathrm{F}$ & $\mathrm{F}$ \\
\hline Masjid Al-Munawwarah & & $\mathrm{O}$ & $\mathrm{F}$ & $\mathrm{F}$ \\
\hline Masjid Nurul Hidayah & & $\mathrm{O}$ & $\mathrm{F}$ & $\mathrm{F}$ \\
\hline Masjid Ilham & 11.714 & 30.880 & 107 & 128 \\
\hline Masjid Aufu Bil 'Uqud & 8.462 & 103.798 & 27 & 11.258 \\
\hline Masjid Taqwa & 11.864 & 94.937 & 38 & 286 \\
\hline \multicolumn{5}{|l|}{ Masjid Nurul Islam } \\
\hline Masjid Asasi & 14.338 & 6.285 .649 & 1.025 & 5.716 \\
\hline Masjid Raudhatul Jannah & & $\mathrm{O}$ & $\mathrm{F}$ & $\mathrm{F}$ \\
\hline Masjid Nurul Huda & & $\mathrm{O}$ & $\mathrm{F}$ & $\mathrm{F}$ \\
\hline Masjid Islamic Center & 17.784 & 159.303 & 1.919 & 308 \\
\hline
\end{tabular}

\subsubsection{Throughput}

Rumus Throughput disajikan pada Persamaan (1)

Throughput $=\frac{\text { Byte s }}{\text { Span Time }}$

Pada jaringan yang sudah diambil pada masjid Jami' Nurul Huda didapai span time 21.016, byte 103.406.

$$
\begin{gathered}
\text { Throughput }=\frac{103.406(\text { byte } s)}{21.016(\text { span time })} \\
=4,920346402740769 \times 8 \\
=39,362.77122192615 \\
=40.80
\end{gathered}
$$

Jadi Throughput pada masjid Jami' Nurul Huda adalah 40.80 bit.

\subsubsection{Packet Loss}

Rumus Packet Loss disajikan pada Persamaan (2).
Pada sampel jaringan yang sudah di ambil oleh peneliti. Pada masjid Jami' Nurul Huda didapai packet 84.

$P L=\frac{84-84}{84} \times 100 \%$

Jadi Packet Loss yang didapa pada masjid Jami’ Nurul Huda adalah 0 .

\subsubsection{Delay}

Rumus Delay disajikan pada Persamaan (3).

Delay $=$ Time2- Time 1

Rata-rata Delay $=$ Total Delay $/$ Packet disajikan pada Tabel 3.

$$
P L=\frac{\text { Paket data Dikirim }- \text { Paket data Diterima }}{\text { Paket Data yang Dikirim }} \times 100 \%
$$


Tabel 3. Delay Masjid Jami’ Nurul Huda

\begin{tabular}{clcc}
\hline No & Time & Source & Destination \\
\hline 1 & 0.061612 & 10.1 .101 .78 & 23.100 .93 .154 \\
2 & 0.989417 & 10.1 .101 .78 & 35.206 .118 .237 \\
3 & 1.437 .453 & 10.1 .101 .78 & 35.206 .118 .237 \\
4 & 1.437 .517 & 10.1 .101 .78 & 35.206 .118 .237 \\
\hline
\end{tabular}

Didapati packet dari delay adalah 277, setelah itu masukkan kedalam rumus.

Delay $=$ Time $2-$ Time 1

Rata-rata Delay $=$ Total Delay $/ 277$

Total Delay $=21.306 .151$

Rata-rata Delay $=76917,51264$

Jadi Delay yang didapat pada masjid Jami' Nurul Huda adalah 21.306.151 dengan rata rata delay $76.917,51264$.

\subsubsection{Jitter}

Rumus Jitter disajikan pada Persamaan (3).

Jitter $=$ Delay $1-$ Delay 2

Rata-rata Jitter $=$ Total jitter $/$ packet

Total Jitter $=1.472 .532$

Rata -rata Jitter $=5316,000038$

Jadi Jitter yang didapat pada masjid Jami' Nurul Huda adalah 1.472.532 dengan rata rata Jitter 5316,000038.

\section{Kesimpulan}

Berdasarkan hasil penelitian di Masjid Padang Panjang, pengaturan bandwidth dan jumlah pengguna membuat jaringan lambat. Sehingga dengan menerapkan metode Quality of Service dapat memperbaiki kecepatan internet yang lambat. Dengan melakukan analisa dan melakukan tes kecepatan internet, Kualitas jaringan internet di Masjid Padang Panjang cukup baik karena jumlah bandwidth 1000 Mbps (1Gbps) untuk 36 Masjid. Dengan menerapkan metode Quality of Service pada jaringan Masjid, diharapkan bisa membantu pegawai Balaikota Padang Panjang mengatasi masalah jaringan yang sering muncul.

\section{Daftar Rujukan}

[1]. Dina, Zulhendra. (2021) Analisis Quality of Service (QoS) Jaringan Virtual Private Network (VPN) dengan menggunakan protokol IPSec (Studi Kasus : SMK Negeri 3 Pariaman) https://doi.org/10.24036/voteteknika.v9i1.111056
[2]. Bensalah, et al. (2019) Quality of Service Performance Evaluation of Next-Generation Network. DOI: 10.1109/CAIS.2019.8769576

[3]. Miraz H, et al., (2017) Simulation and Analysis of Quality of Service (QoS) Parameters of Voice over IP (VoIP) Traffic through Heterogeneous Networks. https://doi.org/10.14569/IJACSA.2017.080732

[4]. M.Mubarak, et al., (2019) Evaluating Quality of Service Traffic Classes on the Megafly Network. DOI:10.1007/978-3-03020656-7_1

[5]. Guntoro, et al., (2020) Evaluasi Performance Jaringan Internet Kampus Menggunakan Quality of Service (QOS). DOI: https://doi.org/10.31849/semaster.v1i1.6139

[6]. M. Mozhaeiv, et al., (2020) Means of Improving the Quality of Service of The Komputer Network of The Forensic Information System. DOI:10.30837/2522-9818.2020.12.057

[7]. [7] Siyamto Y, Saputra A., (2019) Analisis Kualitas Layanan Internet Di Pulau Belakang Padang dengan Metode QoS. DOI: https://doi.org/10.33884/cbis.v7i2.1366

[8]. W Puspita, Y Huda., (2019) Analisis Kualitas Layanan Jaringan Internet WIFI.ID Menggunakan Parameter QoS (Quality of Service). https://doi.org/10.24036/voteteknika.v7i1.103643

[9]. F Witi, A Mude., (2020) Analisis Jaringan Internet Di Universitas Flores Menggunakan Quality of Service (QOS). https://doi.org/10.33884/cbis.v8i1.1797

[10]. Suryani, et al., (2018) Analisa Parameter QOS dan RMC Jaringan Internet Di Politeknik Negeri Sriwijaya

[11]. Rios, et al., (2021) Wideband OFDM-Based Communications in Bus Topology as a Key Enabler for Industry 4.0 Networks. DOI: 10.1109/ACCESS.2021.3104741

[12]. Mohammed, et al., (2019) Wireless Daisy Chain and Tree Topology Networks for Smart Cities. DOI: 10.1109/ICECCT.2019.8869252

[13]. Lin, et al., (2018) Global Genetic Learning Particle Swarm Optimization with Diversity Enhancement by Ring Topology. https://doi.org/10.1016/j.swevo.2018.07.002

[14]. Thai, et al., (2019) Secret Group-Key Generation at Physical Layer for Multi-Antenna Mesh Topology. DOI: 10.1109/TIFS.2018.2837661

[15]. Zhu, et al., (2019) StarNet: Pedestrian Trajectory Prediction using Deep Neural Network in Star Topologi. DOI: 10.1109/IROS40897.2019.8967811

[16]. Vyacheslav Kartashevskiy. Marina Buranova. (2018) Analysis of Packet Jitter in Multiservice Network. DOI: 10.1109/INFOCOMMST.2018.8632085

[17]. Misinem, Gerry Praja Mukti. (2021) Analisis Kualitas Jaringan Nirkabel Dengan Metode Quality Of Service DOI: https://doi.org/10.33557/binakomputer.v3i1.1220 